\title{
Radioprotective effect of lactoferrin in mice exposed to sublethal $\mathrm{X}$-ray irradiation
}

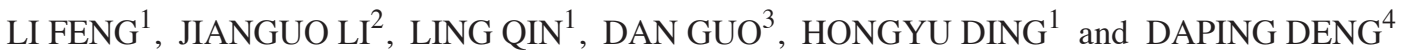 \\ ${ }^{1}$ Ultrasound Department, Qianfoshan Hospital of Shandong Province, Jinan, Shandong 250014; \\ ${ }^{2}$ Department of Human Anatomy, The School of Medicine of Inner Mongolia University for The Nationalities, \\ Tongliao, Inner Mongolia 028041; ${ }^{3}$ Clinical Medicine Department, Taishan Medical University, Taian, \\ Shandong 271016; ${ }^{4}$ Laboratory of Radiation Biology, The Radiation Medical Institute, \\ Shandong Academy of Medical Sciences, Jinan, Shandong 250062, P.R. China
}

Received September 16, 2017; Accepted June 22, 2018

DOI: $10.3892 / \mathrm{etm} .2018 .6570$

\begin{abstract}
The radioprotective effect of lactoferrin (LF) was studied in mice subjected to sublethal X-ray irradiation. The mice were randomly divided into the Control (non-irradiated mice fed a standard diet without LF), IR (irradiated mice fed a standard diet) and IR+LF (irradiated mice fed LF) groups. The mice were fed daily for 7 days prior to irradiation and for 30 continuous days following irradiation. The survival ratio of the mice in the IR+LF group was significantly increased compared with the IR group between days 15 and 30 after irradiation. The body weight of the mice in the IR+LF group was increased compared with the IR group, and the difference was statistically significant. Blood was collected from the mice via the tail vein on days $2,7,14,21$ and 30 following irradiation. The laboratory indicators, including leukocyte, erythrocyte and platelet counts recovered more rapidly following irradiation in the IR+LF group compared with the IR group. Treatment of the irradiated mice with LF significantly reduced the DNA damage. In the hepatic tissue the level of superoxide dismutase in the IR+LF group was significantly increased, while malondialdehyde was significantly decreased compared with the IR group. These findings indicate that LF may prevent radiation damage and may have potential as a treatment for patients with cancer who receive radiotherapy.
\end{abstract}

Correspondence to: Professor Hongyu Ding, Ultrasound Department, Qianfoshan Hospital of Shandong Province, 16766 Jingshi Road, Lixia, Jinan, Shandong 250014, P.R. China

E-mail: qqddf11998@163.com

Professor Daping Deng, Laboratory of Radiation Biology, The Radiation Medical Institute, Shandong Academy of Medical Sciences, 18877 Jingshi Road, Lixia, Jinan, Shandong 250062, P.R. China

E-mail: qyfengli@sina.com

Key words: radioprotection, lactoferrin, X-ray, irradiation, mice

\section{Introduction}

Radiotherapy is a common treatment method for a number of types of human cancer, with approximately half of all patients requiring radiotherapy for palliative or curative purposes (1). However, patients undergoing radiotherapy may develop adverse side-effects, including hematological toxicity, cytopenia, immune suppression and mucosal damage (2). Under ideal conditions, tumor tissue would receive a large dose of radiation, while normal healthy tissues would be protected from radiation injury. Therefore, the pathogenic processes induced by ionizing radiation and non-toxic radioprotective compounds that may protect normal tissues against radiation injury, are currently being extensively researched (3-5). Several compounds, including cysteine, aminothiol and cytokines, are known radioprotectors (6-8). Crescenti et al (9) reported that selenium, zinc and magnesium may also have radioprotective properties. Nishimura et al (10) reported that chitosan increased the hematocrit and survival rate in mice exposed to sublethal X-ray irradiation. Emami et al (11) reported that zinc exerted a protective effect against lethality in irradiated mice.

Lactoferrin (LF) is an $80 \mathrm{kDa}$ iron-binding glycoprotein, which is a component of exocrine secretions, including milk and saliva and is also present in neutrophil granules (12). LF has been reported to serve a role in host defense and has various biological properties, including antimicrobial effects and modulation of cell growth $(13,14)$. In addition to serving a key role in immune homeostasis, LF also reduces oxidative stress and may control excessive inflammatory responses $(13,15,16)$. Recently, Sriramoju et al (17) reported that LF exerts various beneficial effects on humans and animals, including inhibition of carcinogenesis and prevention of drug-induced toxicity. Irradiated mice on an LF diet exhibited a significantly higher survival rate compared with mice fed a standard diet (18). The prevention of chemotherapy-induced ovarian disorders in mice receiving oral LF has also been reported (19). In addition, the use of a gel containing LF in patients with oral cancer who were treated with radiotherapy, increased salivary secretion, inhibited xerostomia and improved oral bacterial flora (20).

However, studies on the radioprotective effects of LF are limited. The aim of the present study was to investigate in vivo 
whether LF may enhance resistance to high doses of ionizing radiation in mice and to elucidate the possible mechanisms of action. To determine this, the survival ratio and hematopoietic system toxicity in mice receiving whole-body, high does (7.0 Gy) irradiation were assessed.

\section{Materials and methods}

Animals and irradiation. Male Balb/c mice (age, 6 weeks; weight, 20-23 g) were purchased from Unilever (Shanghai, China). All mice had free access to water and food; they were kept in a room maintained at $60 \pm 10 \%$ relative humidity and $20 \pm 2{ }^{\circ} \mathrm{C}$ with a $12 \mathrm{~h}$ light/dark cycle. There were 5 mice per cage. A total of 60 mice were randomly assigned into 3 groups ( $n=20$ per group) as follows: i) Control (non-irradiated mice fed a standard diet without LF); ii) IR (whole-body irradiated mice fed a standard diet without LF); and iii) IR+LF (whole-body irradiated mice fed a diet containing $0.1 \%$ bovine LF; Sigma-Aldrich, Merck KGaA, Darmstadt, Germany). The mice in the IR and IR+LF groups were exposed to a sublethal radiation dose (7.0 Gy). The control mice were sham irradiated. The mice were irradiated using a 6-MV linear accelerator at a dose rate of $0.865 \mathrm{~Gy} / \mathrm{min}$ (PRIMUS High Energy; Siemens AG, Munich, Germany). The mice were fed for 7 days prior to irradiation and for 30 continuous days following irradiation. The study protocol was approved by the Ethics Committee of Qianfoshan Hospital of Shandong Province (Jinan, China).

Peripheral blood cell counts. Blood was collected from the mice via the tail vein in EDTA tubes (BD Biosciences, Franklin Lakes, NJ, USA) on days 0, 1, 2, 3, 9, 14, 19 and 29 following irradiation. The blood was centrifuged at $1,000 \mathrm{x}$ g for $20 \mathrm{~min}$ at $20 \pm 2{ }^{\circ} \mathrm{C}$ and evaluated using an automated hematology analyzer (pocH-100i; Sysmex Corporation, Kobe, Japan) to provide the complete blood cell counts. The measurements included leukocyte, erythrocyte and platelet (PLT) counts, as well the hemoglobin. The normal references value of hematological parameters were described previously (21).

Lymphocyte isolation and comet assay. A volume of $0.15 \mathrm{ml}$ whole blood was layered onto the lymphocyte separation medium (cat. no. MRGMA0; R\&D Systems, Inc., Minneapolis, MN, USA) and centrifuged for $2 \mathrm{~min}$ at $3,500 \mathrm{xg}$ at $20 \pm 2^{\circ} \mathrm{C}$. The lymphocytes were subsequently transferred to a $1.5 \mathrm{ml}$ tube containing $1.2 \mathrm{ml} 0.1 \mathrm{M}$ PBS and centrifuged for $5 \mathrm{~min}$ at $2,000 \times \mathrm{g}$ at $20 \pm 2^{\circ} \mathrm{C}$. The lymphocytes were washed twice with PBS. The cells were then suspended in PBS and the density was adjusted to $5-6 \times 10^{4} / \mathrm{ml}$. A comet assay was performed under neutral conditions as described by Banath et al (22), with a slight modification. Specifically, special comet slides were used as opposed to conventional slides. All comet images were analyzed using CASP Lab software (version 1.2.3b2; CASPLab, Wroclaw, Poland) (23) and the percentage of DNA in the Olive Tail Moment (OTM) was recorded to characterize the lymphocytic DNA damage.

Biochemical analysis. The livers were removed, fixed in 4\% paraformaldehyde solution at room temperature for $20 \mathrm{~min}$ and ground 30 days after radiation ( 5 mice per group). The obtained cells were washed with PBS and suspended in EDTA.
Superoxide dismutase (SOD) and malondialdehyde (MDA) activities in the liver were analyzed using SOD and MDA assay kits (Beyotime Institute of Biotechnology, Haimen, China) according to the manufacturer's protocol.

Statistical analysis. Data are presented as the mean \pm standard deviation ( $\geq 5$ mice per group at each time point). Statistical analysis was performed using one-way analysis of variance with a post hoc Tukey's test (multiple comparison test) to determine the significance of differences among multiple groups. $\mathrm{P}<0.05$ was considered to indicate a statistically significant difference. SPSS version 13.0 software (SPSS, Inc., Chicago, IL, USA) was used for the analyses.

\section{Results}

$L F$ increases the survival rate of mice exposed to irradiation. In the present study, mice in the IR and IR+LF groups were exposed to $7 \mathrm{~Gy}$ radiation. The survival rate was monitored on days 1-30 following irradiation (Fig. 1). Kaplan-Meier analysis indicated that survival rates were significantly higher in the IR+LF group compared with the IR group between day 12 and $30(\mathrm{P}<0.05)$. On day 30 the survival rate of the $\mathrm{IR}+\mathrm{LF}$ group was $50 \%$ and the survival rate of the IR group was $33 \%$. The survival rate in the IR+LF group was significantly higher compared with that of the IR group $(\mathrm{P}<0.05)$. The differences between the IR+LF group and the control were also statistically significant $(\mathrm{P}<0.05)$. These results suggest that LF increased the survival rate of mice following exposure to radiation.

$L F$ reduces the radiation-induced decrease in body weight. The body weights of the mice were measured at various time points following irradiation and the mean weight \pm standard deviation was calculated among surviving mice (Fig. 2). The results revealed that the body weights significantly increased in the control group, remained mostly constant in the IR+LF group and decreased slightly in the IR group between day 8 and 10 after irradiation. Statistical analysis indicated that body weight was significantly higher in the IR+LF group compared with the IR group between days 20 and $30(\mathrm{P}<0.05)$. Furthermore, the body weights of the mice in the control group were significantly greater compared with the IR+LF group on days 20 and $25(\mathrm{P}<0.05)$. Furthermore, on day 30, no significant differences in body weight were identified between the control group and the IR+LF group.

\section{LF enhances hematological repopulation following} whole-body irradiation. Hematological parameters were recorded following irradiation, including changes in the leukocyte count (Fig. 3). The leukocyte count in the IR+LF group exhibited a progressive decline to $1.9 \times 10^{9} / 1$ on day 3 . In addition, the leukocyte count appears to stay steady between days 9 and 14 in the IR+LF group at $\sim 2.6 \times 10^{3} / \mu 1$. On day 29 the leukocyte count of the IR+LF mice had stabilized to within the normal range $\left(7.6 \times 10^{9}-10.9 \times 10^{9} / 1\right)(21)$. The significant difference was identified between the control group and the IR+LF group except on day $29(\mathrm{P}<0.05)$. However, the leukocyte count of the IR mice remained low $\left(0.35 \times 10^{9} / 1\right)$ until day 14 . Between day 9 and 29, the leukocyte counts in the IR group 


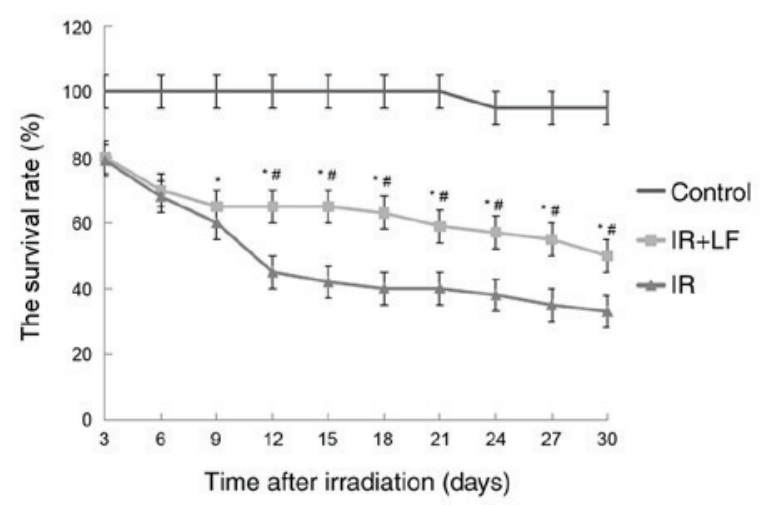

Figure 1. Survival rates of irradiated mice. Each vertical bar indicates the standard deviation. Data are presented as the mean \pm standard deviation (5 mice/group/time point). IR, irradiated mice fed a standard diet; IR+LF, irradiated mice fed lactoferrin. ${ }^{\text {}} \mathrm{P}<0.05$ vs. the control group; ${ }^{\#} \mathrm{P}<0.05$ vs. the IR group.

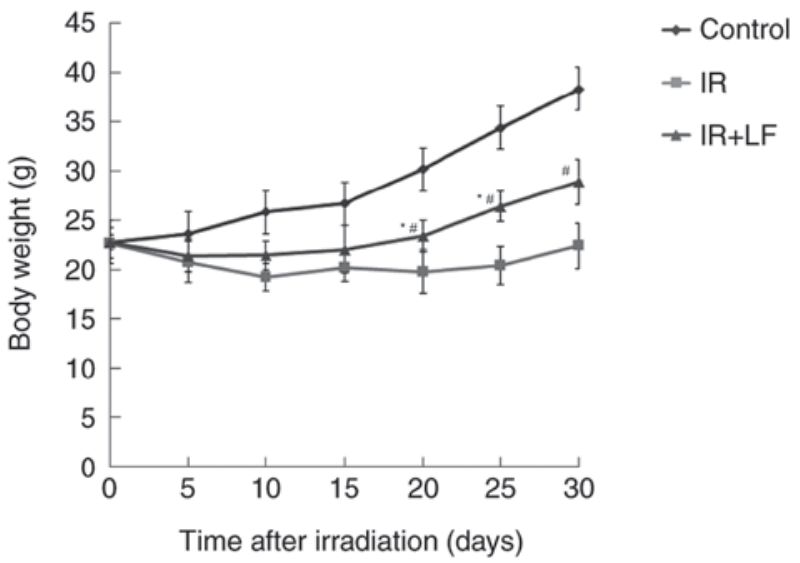

Figure 2. Body weights of irradiated mice. Each vertical bar indicates the standard deviation. Data are presented as the mean \pm standard deviation (5 mice/group/time point). IR, irradiated mice fed a standard diet; IR+LF, irradiated mice fed lactoferrin. ${ }^{\text {P }} \mathrm{P}<0.05$ vs. the control group; ${ }^{\#} \mathrm{P}<0.05$ vs. the IR group.

were significantly lower compared with the IR+LF group $(\mathrm{P}<0.05)$.

In the IR+LF group the erythrocyte count decreased to $4.6 \times 10^{12} / 1$ on day 9 and gradually recovered to a value of $6.47 \times 10^{12} / 1$ on day 14 (Fig. 4). No significant difference was identified between the control group and the IR+LF group on day 29. In the IR group the erythrocyte count decreased to $2.17 \times 10^{12} / 1$ on day 9 . From day 9 , the erythrocyte count in the IR+LF group was significantly greater compared with the IR group $(\mathrm{P}<0.05)$. The control group was significantly greater compared with the IR group between day 3 and $29(\mathrm{P}<0.05)$. These results indicate that LF improved erythrocyte repopulation in the mice.

Following a decrease post irradiation, the PLT count in the IR+LF group was restored to within a normal range on day 19 (Fig. 5) (21). However, in the IR group, the PLT count decreased to a minimum value at day 9 and slowly increased to a normal level (21) by day 29 . The IR+LF group was significantly greater compared with the IR group between day 1 aand 9 , and 19 and $29(\mathrm{P}<0.05)$. The control group was significantly

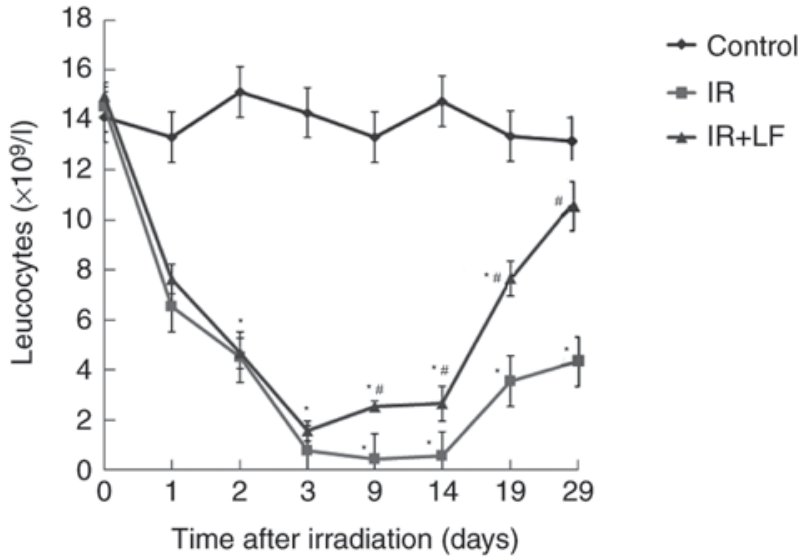

Figure 3. Leukocyte counts of mice following irradiation. Each vertical bar indicates the standard deviation. Data are presented as the mean \pm standard deviation ( 5 mice/group/time point). IR, irradiated mice fed a standard diet; IR+LF, irradiated mice fed lactoferrin. ${ }^{*} \mathrm{P}<0.05$ vs. the control group; ${ }^{"} \mathrm{P}<0.05$ vs. the IR group.

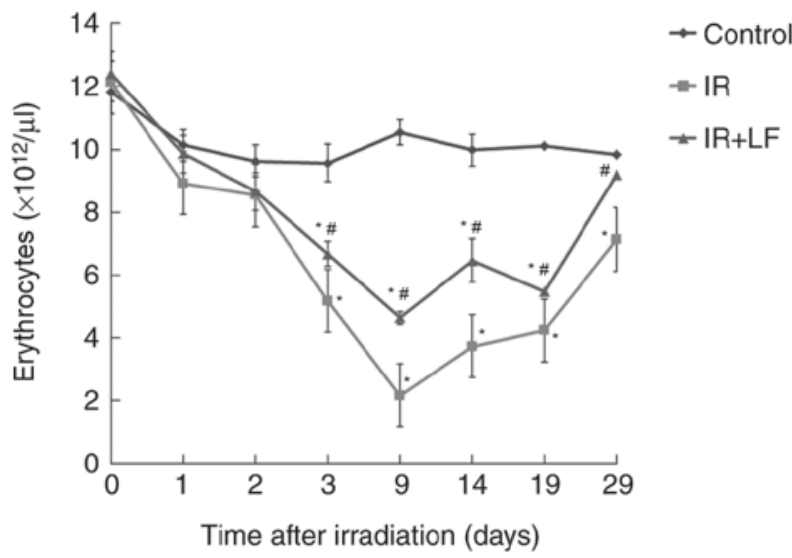

Figure 4. Erythrocite counts of mice following irradiation. Each vertical bar indicates the standard deviation. Data are presented as the mean \pm standard deviation (5 mice/group/time point). IR, irradiated mice fed a standard diet; IR+LF, irradiated mice fed lactoferrin. " $\mathrm{P}<0.05$ vs. the control group; ${ }^{\#} \mathrm{P}<0.05$ vs. the IR group.

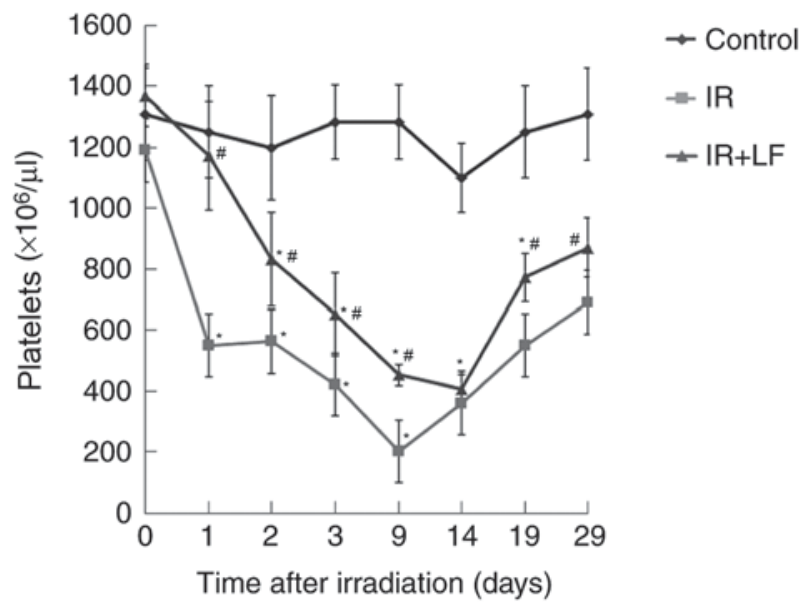

Figure 5. Platelet counts of mice following irradiation. Each vertical bar indicates the standard deviation. Data are presented as the mean \pm standard deviation (5 mice/group/time point). IR, irradiated mice fed a standard diet; IR+LF, irradiated mice fed lactoferrin. ${ }^{*} \mathrm{P}<0.05$ vs. the control group; ${ }^{*} \mathrm{P}<0.05$ vs. the IR group. 
Table I. MDA level and SOD activity in hepatic tissue.

\begin{tabular}{lcc}
\hline Group & SOD $(\mathrm{U} / \mathrm{ml})$ & MDA $(\mathrm{pmol} / \mathrm{l})$ \\
\hline Control & $41.25 \pm 0.41$ & $4.31 \pm 0.02$ \\
IR & $21.52 \pm 0.24^{\mathrm{a}}$ & $7.31 \pm 0.12^{\mathrm{a}}$ \\
IR+LF & $42.56 \pm 0.71^{\mathrm{b}}$ & $4.98 \pm 0.42^{\mathrm{b}}$ \\
\hline
\end{tabular}

${ }^{\mathrm{a}} \mathrm{P}<0.05$ vs. the Control. ${ }^{\mathrm{b}} \mathrm{P}<0.05$ vs. the IR group. Data are presented as the mean \pm standard deviation. $n=5$ per group. IR, irradiated mice fed a standard diet; IR+LF, irradiated mice fed lactoferrin; SOD, superoxide dismutase.

greater compared with the IR and IR+LF group $(\mathrm{P}<0.05)$. No significant difference was identified between the control group and the IR+LF group on day 29. These results indicate that LF improved PLT repopulation in the mice.

The results also demonstrated that IR induced a significant decrease in the level of hemoglobin between days 7 and 21 following irradiation. Post irradiation, the hemoglobin levels in the IR+LF and IR groups were significantly lower compared with the control group $(\mathrm{P}<0.05$; Fig. 6). The hemoglobin level recovered faster and was consistently increased in the IR+LF group compared with the IR group. The hemoglobin levels in the IR+LF group were significantly higher compared with the IR group $(\mathrm{P}<0.05)$. These results indicate that LF significantly enhanced the recovery of hemoglobin during the experimental period compared with the IR group.

$L F$ increases antioxidant capacity. The MDA level is associated with lipid peroxidation in the liver (24). The MDA level in hepatic tissue was significantly lower in the IR+LF group compared with the IR group, which suggests that the LF diet prevented hepatic lipid peroxidation (Table I). SOD activity indicates the generation of oxidative stress (25). The protective response to oxidative damage in the liver of IR mice decreased significantly following irradiation compared with the control group. However, the LF diet significantly prevented the change in SOD activity compared with the IR group.

LF decreases the OTM of lymphocytes following irradiation. Irradiation led to the breakage of DNA chains. The OTM percentage 24,48 and $72 \mathrm{~h}$ post irradiation in the IR+LF group was significantly greater and lesser compared with the control and IR groups, respectively $(\mathrm{P}<0.05$; Fig. 7). Following unwinding, DNA was affected by the electric field in the electrophoresis liquid, forming the distinctive comet tail formation (Fig. 8).

\section{Discussion}

A number of substances with radioprotective properties have been previously reported (26). Intraperitoneal injection of purified ginseng extract following $6.5 \mathrm{~Gy} \mathrm{X}$-ray irradiation significantly increased the 30 day survival rate in mice (27). In addition, Shigoka extract prepared from Acathopanax senticosus was also reported to increase the post-irradiation survival rate in mice (28). The aim of the present study was to demonstrate the protective effects exerted by LF against radiation-induced injury in mice. The results demonstrated

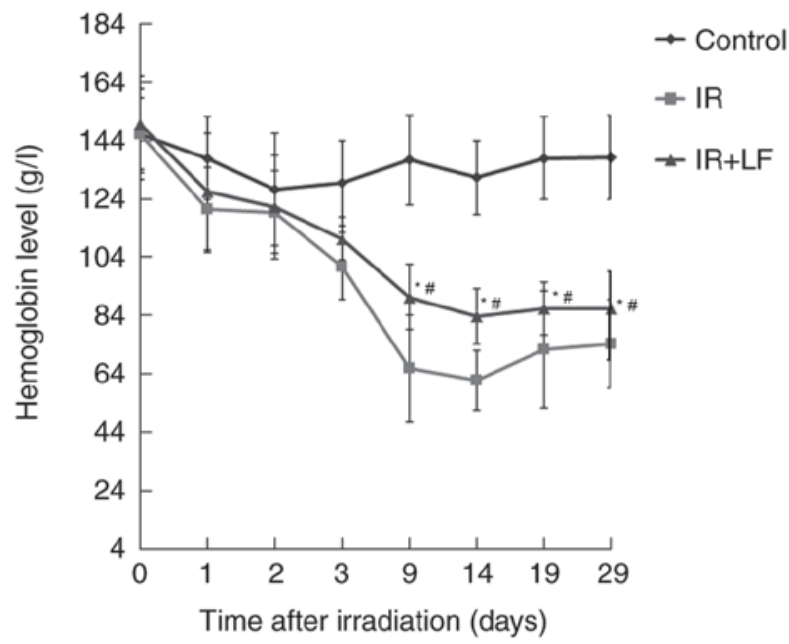

Figure 6. Hemoglobin levels of mice following irradiation. Each vertical bar indicates the standard deviation. Data are presented as the mean \pm standard deviation (5 mice/group/time point). IR, irradiated mice fed a standard diet; IR+LF, irradiated mice fed lactoferrin. ${ }^{*} \mathrm{P}<0.05$ vs. the control group; ${ }^{\#} \mathrm{P}<0.05$ vs. the IR group.

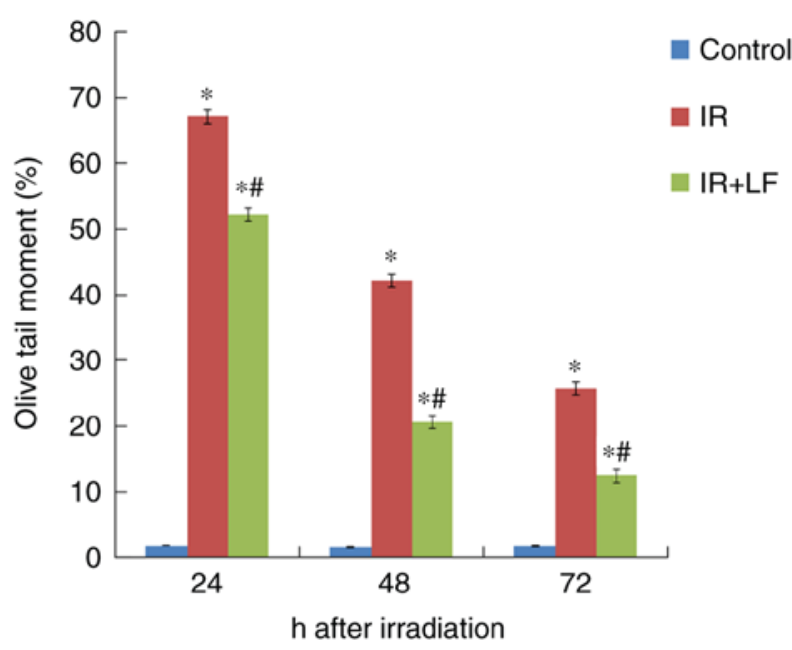

Figure 7. Olive Tail Moment of lymphocytes following irradiation. Data are presented as the mean \pm standard deviation ( 5 mice/group/time point). IR, irradiated mice fed a standard diet; IR+LF, irradiated mice fed lactoferrin. ${ }^{*} \mathrm{P}<0.05$ vs. the control group; ${ }^{\#} \mathrm{P}<0.05$ vs. the IR group.

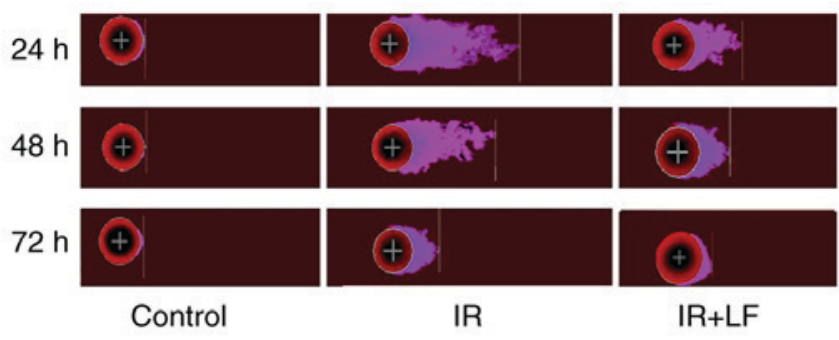

Figure 8. Comet images of lymphocytes following irradiation. Comet images were analyzed by CASPLab software.

that at day 30 following irradiation the survival rate of the mice was $17 \%$ higher in IR+LF group compared with the mice in the IR group, demonstrating that an LF diet significantly improves survival rates. 
It has been previously established that the survival rate of mice following exposure to a sublethal dose of radiation depends, on the recovery of the hematopoietic system $(29,30)$. To determine whether LF protects mice from IR-induced hematopoietic system injury, the mice were exposed to X-ray irradiation at a dose of 7.0 Gy.

It is known that the number of leukocytes is correlated with the radiation dose (31). The IR+LF group exhibited a rapid increase in the leukocyte count from day 14 onwards and on day 29 the count was restored to normal levels. However, in the IR group, the leukocyte count began to increase at day 14 in the IR group, but the count remained at a lower level. These results indicate that LF stimulated the recovery of leukocytes and exerted a radioprotective effect.

In the IR group the PLT count exhibited an initial decline following X-ray irradiation and on day 9 the count was at its lowest level, however it returned to normal by day 29. The IR+LF group exhibited a faster increase in PLTs compared with the IR group and they recovered to near normal levels at day 19. It has been previously reported that when infants were fed an LF-supplemented infant formula, their hemoglobin value was increased compared with the group fed a conventional infant formula (32); similar results were also observed in female marathon runners (33). In the present study, the red blood cell count and hemoglobin levels were increased in the IR+LF group compared with the IR group following irradiation, which indicates that LF exerted hematopoietic or radioprotective effects.

Radiation may increase the oxidative capacity and induce damage to cellular molecules; previous biochemical studies have been performed to define normal MDA and SOD levels in liver tissue (34-36). The results of the present study revealed that the MDA level in the hepatic tissue was significantly lower in the IR+LF group compared with the IR group, while SOD activity was significantly increased. These results reveal that LF exerted a protective effect on cellular molecules against radiation-induced oxidative damage.

The comet assay, which detects DNA damage, has been widely used in radiation biology (37-40). The comet assay is a rapid and sensitive microdosimetric technique, particularly useful in radiation accidents (41). In the IR+LF and IR groups, the comet assay was used to observe the degree of DNA damage by irradiation. The IR group exhibited a substantial increase in DNA damage, even at 30 days post irradiation, while the IR+LF mice exhibited significantly reduced DNA damage. The present study demonstrated that significant differences were identified between the IR group and IR+LF group following irradiation. Therefore, the comet assay demonstrated that LF effectively reduced radiation-induced DNA injury.

In conclusion, the results of the present study suggest that LF increases PLT and leukocyte counts and reduces DNA damage in mice following high-dose irradiation. In the future LF may have potential as a radioprotector to reduce the adverse effects of radiotherapy. However, the exact mechanism of action of LF has not yet been fully elucidated. Therefore, further studies are required to determine whether radioscavenging or trapping is involved in this effect and to clarify the value of LF within the field of radiation protection.

\section{Acknowledgements}

Not applicable.

\section{Funding}

The present study was supported by the Natural Science Foundation of Shandong (grant no. 2010GSF10251), the Natural Science Foundation of Shandong (grant no. ZR2014YL027), the Natural Science Foundation of Inner Mongolia Autonomous Region of China (grant no. 2016MS0814) and the National Natural Science Foundation of China (grant no. 81760567).

\section{Availability of data and materials}

All data generated or analyzed during the current study are included in this published article.

\section{Authors' contributions}

LF fed the animals, collected blood from the mice and was a major contributor in the writing of the manuscript. DG performed the irradiation. DPD performed the histological examination. HYD performed the superoxide dismutase and malondialdehyde ELISAs. LQ analyzed the peripheral blood cells. JGL performed the lymphocyte isolation and comet assays. All authors read and approved the final manuscript.

\section{Ethics approval and consent to participate}

The present study was approved by the Ethics Committee of Qianfoshan Hospital Affiliated to Shandong University.

\section{Patient consent for publication}

Not applicable.

\section{Competing interests}

The authors declare that they have no competing interests.

\section{References}

1. Jung J, Kim H, Yoon SM, Cho B, Kim YJ , Kwak J and Kim JH: Targeting accuracy of image-guided stereotactic body radiation therapy for hepatocellular carcinoma in real-life clinical practice: In vivo assessment using hepatic parenchymal changes on Gd-EOB-DTPA-enhanced magnetic resonance images. Int J Radiat Oncol Biol Phys S0360-3016: 30811-30813, 2018.

2. Kavitha M, Mubeen K and Vijayalakshmi KR: A study on Evaluation of efficacy of bethanechol in the management of chemoradiation-induced xerostomia in oral cancer patients. J Oral Maxillofac Pathol 21: 459-460, 2017.

3. Szybalski W: Molecular events resulting in radiation injury, repair and sensitization of DNA, Radiation research. Supplement 7: 147-159, 1967.

4. Keramati Yazdi F, Shabestani Monfared A, Tashakkorian H, Mahmoudzadeh A and Borzoueisileh S: Radioprotective effect of Zamzam (alkaline) water: A cytogenetic study. J Environ Radioact 167: 166-169, 2017.

5. Kirakosyan G, Torgomyan H, Malakyan M, Bajinyan S and Trchounian A: Protective effect of some amino acids synthesized derivatives and their chelates on Escherichia coli under X-ray irradiation. Indian J Biochem Biophys 50: 289-295, 2013. 
6. Greenberger JS, Clump D, Kagan V, Bayir H, Lazo JS, Wipf P, Li S, Gao X and Epperly MW: Strategies for discovery of small molecule radiation protectors and radiation mitigators. Front Oncol 1: 59, 2012.

7. Kunwar A, Adhikary B, Jayakumar S, Barik A, Chattopadhyay S, Raghukumar S and Priyadarsini KI: Melanin, a promising radioprotector: Mechanisms of actions in a mice model. Toxicol Appl Pharmacol 264: 202-211, 2012.

8. Rostami A, Moosavi SA, Changizi V and Abbasian Ardakani A: Radioprotective effects of selenium and vitamin-E against 6MV $\mathrm{X}$-rays in human blood lymphocytes by micronucleus assay. Med J Islam Repub Iran 30: 367, 2016.

9. Crescenti E, Croci M, Medina V, Sambuco L, Bergoc R and Rivera E: Radioprotective potential of a novel therapeutic formulation of oligoelements Se, $\mathrm{Zn}, \mathrm{Mn}$ plus Lachesis muta venom. J Radiat Res 50: 537-544, 2009.

10. Nishimura Y, Kim HS, Ikota N, Arima H, Bom HS, Kim YH, Watanabe Y, Yukawa M and Ozawa T: Radioprotective effect of chitosan in sub-lethally X-ray irradiated mice. J Radiat Res 44 53-58, 2003.

11. Emami S, Hosseinimehr SJ, Taghdisi SM and Akhlaghpoor S Kojic acid and its manganese and zinc complexes as potential radioprotective agents. Bioorg Med Chem Lett 17: 45-48, 2007.

12. Bruni N, Capucchio MT, Biasibetti E, Pessione E, Cirrincione S, Giraudo L, Corona A and Dosio F: Antimicrobial activity of lactoferrin-related peptides and applications in human and veterinary medicine. Molecules 21 pii: E752, 2016.

13. Baveye S, Elass E, Mazurier J, Spik G and Legrand D: Lactoferrin A multifunctional glycoprotein involved in the modulation of the inflammatory process. Clin Chem Lab Med 37: 281-286, 1999.

14. Berlutti F, Pantanella F, Natalizi T, Frioni A, Paesano R, Polimeni A and Valenti P: Antiviral properties of lactoferrin-a natural immunity molecule. Molecules 16: 6992-7018, 2011.

15. Inamori M, Togawa J, Matsumoto S, Harad K, Matsuura M, Iida H, Akimoto K, Endo H, Nonaka T, Takahashi H, et al: Protective effect of lactoferrin on acute acid reflux-induced esophageal mucosal damage. Hepatogastroenterology 61: $1595-1600,2014$

16. Kruzel ML and Zimecki M: Lactoferrin and immunologic dissonance: Clinical implications. Arch Immunol Ther Exp (Warsz) 50: 399-410, 2002.

17. Sriramoju B, Kanwar RK and Kanwar JR: Lactoferrin induced neuronal differentiation: A boon for brain tumours. Int J Dev Neurosci 41: 28-36, 2015

18. Sakai M, Matsushita T, Hoshino R, Ono H, Ikai K and Sakai T: Identification of the protective mechanisms of Lactoferrin in the irradiated salivary gland. Sci Rep 7: 9753, 2017.

19. Horiuchi Y, Higuchi T, Tatsumi K, Takakura K, Fujii S and Konishi I: Lactoferrin is associated with a decrease in oocyte depletion in mice receiving cyclophosphamide. Fertil Steril 91 (5 Suppl): S2069-S2078, 2009.

20. Nagy K, Urban E, Fazekas O, Thurzo L and Nagy E: Controlled study of lactoperoxidase gel on oral flora and saliva in irradiated patients with oral cancer. J Craniofac Surg 18: 1157-1164, 2007.

21. Bella LM, Fieri I, Tessaro FHG, Nolasco EL, Nunes FPB, Ferreira SS, Azevedo CB and Martins JO: Vitamin D modulates hematological parameters and cell migration into peritoneal and pulmonary cavities in alloxan-diabetic mice. Biomed Res Int 2017: 7651815, 2017.

22. Banath JP, Fushiki M and Olive PL: Rejoining of DNA singleand double-strand breaks in human white blood cells exposed to ionizing radiation. Int J Radiat Biol 73: 649-660, 1998.

23. Końca K, Lankoff A, Banasik A, Lisowska H, Kuszewski T, Góźdź S, Koza Z and Wojcik A: A cross-platform public domain $\mathrm{PC}$ image-analysis program for the comet assay. Mutat Res 534: $15-20,2003$
24. El-Mihi KA, Kenawy HI, El-Karef A, Elsherbiny NM and Eissa LA: Naringin attenuates thioacetamide-induced liver fibrosis in rats through modulation of the PI3K/Akt pathway. Life Sci 187: 50-57, 2017

25. Jindal A, Mahesh R, Bhatt $S$ and Pandey D: Molecular modifications by regulating cAMP signaling and oxidant-antioxidant defence mechanisms, produce antidepressant-like effect: A possible mechanism of etazolate aftermaths of impact accelerated traumatic brain injury in rat model. Neurochem Int 111: 3-11, 2017.

26. Smith TA, Kirkpatrick DR, Smith S, Smith TK, Pearson T, Kailasam A, Herrmann KZ, Schubert J and Agrawal DK: Radioprotective agents to prevent cellular damage due to ionizing radiation. J Transl Med 15: 232, 2017.

27. Verma P, Jahan S, Kim TH and Goyal PK: Management of radiation injuries by panax ginseng extract. J Ginseng Res 35: 261-271, 2011.

28. Jagetia GC and Baliga MS: Polyherbal extract of septilin protects mice against whole body lethal dose of gamma radiation. Phytother Res 18: 619-623, 2004.

29. Liu C, Liu J, Hao Y, Gu Y, Yang Z, Li H and Li R $6,7,3^{\prime}, 4^{\prime}$-Tetrahydroxyisoflavone improves the survival of whole-body-irradiated mice via restoration of hematopoietic function. Int J Radiat Biol 93: 793-802, 2017.

30. Li ZT, Wang LM, Yi LR, Jia C, Bai F, Peng RJ, Yu ZY, Xiong GL, Xing S, Shan YJ, et al: Succinate ester derivative of $\delta$-tocopherol enhances the protective effects against ${ }^{60} \mathrm{Co} \gamma$-ray-induced hematopoietic injury through granulocyte colony-stimulating factor induction in mice. Sci Rep 7: 40380, 2017.

31. Erexson GL, Kligerman AD, Bryant MF, Sontag MR and Halperin EC: Induction of micronuclei by X-radiation in human, mouse and rat peripheral blood lymphocytes. Mutat Res 253: 193-198, 1991.

32. King JC Jr, Cummings GE, Guo N, Trivedi L, Readmond BX, Keane V, Feigelman S and de Waard R: A double-blind, placebo-controlled, pilot study of bovine lactoferrin supplementation in bottle-fed infants. J Pediatr Gastroenterol Nutr 44: 245-251, 2007.

33. Koikawa N, Nagaoka I, Yamaguchi M, Hamano H, Yamauchi K and Sawaki K: Preventive effect of lactoferrin intake on anemia in female long distance runners. Biosci Biotechnol Biochem 72: 931-935, 2008.

34. Yaribeygi H, Mohammadi MT and Sahebkar A: Crocin potentiates antioxidant defense system and improves oxidative damage in liver tissue in diabetic rats. Biomed Pharmacother 98: 333-337, 2017.

35. Koc M, Taysi S, Emin Buyukokuroglu M and Bakan N: The effect of melatonin against oxidative damage during total-body irradiation in rats. Radiat Res 160: 251-255, 2003.

36. Zhang B, Su Y, Ai G, Wang Y, Wang T and Wang F: Involvement of peroxiredoxin I in protecting cells from radiation-induced death. J Radiat Res 46: 305-312, 2005.

37. Hoffmann H and Speit G: Assessment of DNA damage in peripheral blood of heavy smokers with the comet assay and the micronucleus test. Mutat Res 581: 105-114, 2005.

38. Li J, Wang Y, DU L, Xu C, Cao J, Wang Q, Liu Q and Fan F: Nested PCR for mtDNA-4977-bp deletion and comet assay for DNA damage-a combined method for radiosensitivity evaluation of tumor cells. Oncol Lett 7: 1083-1087, 2014.

39. Olive PL, Banáth JP and Durand RE: Heterogeneity in radiation-induced DNA damage and repair in tumor and normal cells measured using the 'comet' assay. 1990. Radiat Res 178: AV35-AV42, 2012.

40. Seidel C, Lautenschlager C, Dunst J and Muller AC: Factors influencing heterogeneity of radiation-induced DNA-damage measured by the alkaline comet assay. Radiat Oncol 7: 61,2012.

41. Sirota NP and Kuznetsova EA: The comet assay application in radiobiological investigations. Radiats Biol Radioecol 50: 329-339, 2010 (In Russian). 